\section{Adenosquamous carcinoma in a gastroenteorstomy stoma}

Squamous or mixed adenosquamous carcinoma of the stomach is extremely rare, and such a tumour arising in a gastroenterostomy stoma has apparently never been reported. In presenting this case we wish to adduce evidence for the occurrence of adenosquamous carcinoma in a gastroenterostomy stoma and comment on the diagnostic problems such a lesion poses.

\section{Case report}

A 75-year-old man, who had had a gastroenterostomy 42 years previously, presented with a three-week history of vomiting and burning epigastric pain. On examination he was thin and pale. There was no lymphadenopathy. The liver was not palpable, but there was a suspicion of an epigastric mass $\mathrm{Hb}$ was $8.8 \mathrm{~g} / \mathrm{dl}$ and white cell count $10.3 \times 10^{9} / 1\left(10300 / \mathrm{mm}^{3}\right)$. A barium meal examination showed the anastomosis to be patent but rigid. At gastroscopy the mucosa at the stoma was oedematous and reddened but elsewhere appeared normal. Two biopsy specimens showed only inflammatory changes.

At laparotomy the anastomosis was found to be ulcerated and surrounded by a mass extending to the liver, which was first thought to be inflammatory. A frozen section biopsy from this region of the liver, however, showed a carcinoma, almost entirely squamous in appearance (see figure). The anastomosis, the distal end of the stomach, and the adjacent jejunum were removed and an antecolic gastrojejunostomy was refashioned.

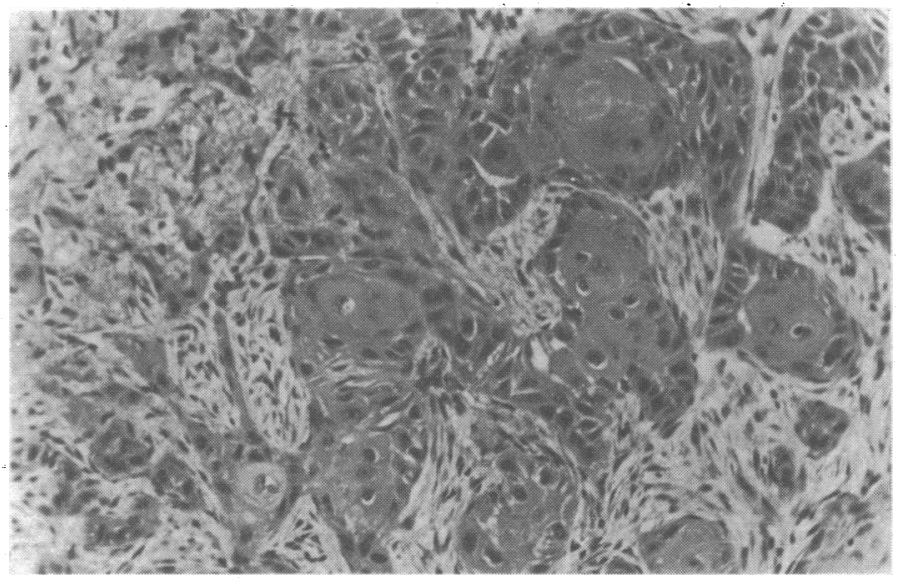

Section of liver biopsy showing infiltrating carcinoma of squamous appearance in a fibrous stroma. (Haematoxylin and eosin. $\times 33.65$.)

Histologically, an ulcerated tumour was found encircling the gastroenterostomy. The greater part was composed of islands of malignan squamous epithelium showing keratinisation and pearl formation. Groups of malignant glands were also present, and at the stoma proximally a transformation between normal and malignant glands was evident. The adjacent gastric mucosa showed neither squamous nor intestinal metaplasia. After initial recovery the patient's condition deteriorated and he died. Permission for necropsy was not obtained.

\section{Comment}

The risk of developing carcinoma of the stomach is generally considered to be increased after gastric surgery for benign conditions, ${ }^{1}$ although conflicting views have been held. In the cases described the most common site of origin has been the pylorus, followed by the body of the stomach. Even when a gastroenterostomy has been performed only a minority have been restricted to the stoma itself. ${ }^{3}$

Histologically, the lesions have been adenocarcinomas showing variable differentiation. The incidence of primary gastric squamous or adenosquamous carcinoma is low. If those atso affecting the lower oesophagus are excluded (since these cannot be accepted with certainty as being of gastric origin) the incidence has been reported as $0.04-0.7 \%$, and no record has been found of this type of tumour affecting a gastroenterostomy stoma.

Theories proposed for the occurrence in the stomach of malignant squamous tissue have been development from a mucosal totipotentia cell, ectopic squamous epithelium, squamous metaplasia in either normal or malignant glandular epithelium, or the endothelium of blood vessels in the gastric wall.4 Transition between normal and malignant gastric glands in our case tends to support a squamous metaplasia of a pre-existing glandular carcinoma.

The long period between the initial surgery and the development of carcinoma has been emphasised. ${ }^{2} 3$ The risk is increased sixfold in patients operated on 25 years or more previously. ${ }^{5}$ Continuous exposure to reflux of bile and intestinal or pancreatic juices is suggested as a chronic irritating factor leading to mucosal damage.

From a practical standpoint our patient's symptoms suggested simple stomal ulceration. We have reported this case to emphasise the suspicion that must be attached to the development of gastrointestinal symptoms many years after gastric surgery and to the possibility of a primary gastric tumour when malignant squamous tissue is found in a liver biopsy specimen.

We are indebted to $\mathrm{Mr} \mathrm{A} \mathrm{H}$ Haysom for permission to report clinical details of this case and to Mrs W Jones for typing the manuscript.

1 Gough, D C, and Craven, J L, Gut, 1975, 16, 843.

2 Gazzola, L M, and Saegesser, F, fournal of Surgical Oncology, 1975, 7, 293.

3 Aronson, A R, and Darling, D R, Gastroenterology, 1959, 36, 686.

4 Strauss, R, Heskel, S, and Fortmann, D J, Cancer, 1969, 24, 985.

5 Stalsberg, H, and Taksdal, S, Lancet, 1971, 27, 1175.

(Accepted 27 September 1977)

Department of Histopathology, The Royal Hampshire County Hospital, Winchester, Hants

ROSE BUCHANAN, MB; MRCPATH, senior registrar

M J SWORN, MB, MRCPATH, consultan

\section{Reversal of finger clubbing after resection of a leiomyoma of the ileum}

Finger clubbing is associated with various diseases, but has not, so far as we are aware, been associated with a leiomyoma of the ileum. This case report is of such an association, the finger clubbing disappearing after the removal of the tumour.

\section{Case report}

A 23-year-old man presented with a six-month history of colicky abdominal pain, diarrhoea, and $13 \mathrm{~kg}$ weight loss. He was emaciated with gross finger clubbing, visible abdominal peristalsis, and a mass in the right iliac fossa. The concentration of haemoglobin was $10.6 \mathrm{~g} / \mathrm{dl}$, serum vitamin $B_{12} 120 \mathrm{ng} / \mathrm{l}(120 \mathrm{pg} / \mathrm{ml})$, serum folate less than $0.1 \mu \mathrm{g} / \mathrm{l}(0.1 \mathrm{ng} / \mathrm{ml})$, and serum albumin $28 \mathrm{~g} / \mathrm{l}$, the other liver function tests being normal. A chest $x$-ray film was normal, as were the results of a barium enema and jejunal, liver, and rectal biopsies. A barium follow through showed dilatation of the small bowel, with a stenotic area in the ileum. A laparotomy showed that the small bowel was dilated, but otherwise macroscopically normal, except in the mid ileum, where there was an intussuscepting "dumb-bell" tumour. The mid ileum was resected, the patient making an uncomplicated recovery. Histologically the tumour was a leiomyoma of the ileum.

Three months after operation the patient was asymptomatic, and had put on $10 \mathrm{~kg}$ in weight. His haemoglobin, serum $B_{12}$, folate, and albumin concentrations were normal. A striking feature was that his finger clubbing had almost disappeared.

\section{Comment}

Such are the nature of the diseases commonly associated with finger clubbing that reversal of this sign would seem uncommon, although it is well described after improvement in health in patients with Crohn's disease. ${ }^{1}$ The aetiology of finger clubbing is unknown, but it is tempting to speculate that dietary malabsorption may be relevant in some instances, as clubbing is seen in coeliac and inflammatory bowel disease. Our patient with longstanding small-bowel obstruction had clear evidence of malabsorption, presumably secondary to 
bacterial overgrowth in the intestinal lumen. After relief of the smallbowel obstruction by removal of his tumour, one would assume that bacterial overgrowth would not be a feature, and certainly three months after his operation there were no clinical or biochemical features of malabsorption. This may be relevant to the disappearance of our patient's clubbing.

${ }^{1}$ Fielding, J F, and Cooke, W T, Gut, 1971, 12, 442.

(Accepted 27 September 1977)

\section{General Hospital, Nottingham NG1 6HA}

R FERGUSON, MD, MRCP, senior medical registrar

P J TOGHILL, MD, FRCP, consultant physician

Department of Surgery, University of Nottingham

J BOURKE, MA, FRCS, senior lecturer

\section{Primary Salmonella typhi meningitis in an adult}

Meningitis due to Salmonella typhi is rare and usually occurs as a complication during typhoid fever. We report a case of $S$ typhi meningitis that occurred as a primary illness in an otherwise healthy adult.

\section{Case report}

A 24-year-old woman dental surgeon gave a two-day history of fever, vomiting, and headache of acute onset, with no associated bowel symptoms. She had been in good health and had been vaccinated against typhoid two years previously. Her history was otherwise insignificant. Examination showed a febrile patient of average build. The cardiovascular and respiratory systems were clinically normal. The abdomen was soft, with no distension, tenderness, or hepatosplenomegaly. Although conscious and rational, the patient was listless and uninterested in her surroundings. Neck rigidity was severe, and Kernig's sign was positive. The rest of the neurological examination, including funduscopy, gave normal results.

The white cell count was $17.2 \times 10^{9} / 1\left(17200 / \mathrm{mm}^{3}\right)$, with $92 \%$ neutrophils, $6 \%$ lymphocytes, and $2 \%$ monocytes. Results of urine analysis and serum electrolyte and blood urea tests were normal. The cerebrospinal fluid (CSF) was turbid and under tension, with proteins $5 \mathrm{~g} / 1$ and glucose $3.7 \mathrm{mmol} / 1$ $(67 \mathrm{mg} / 100 \mathrm{ml})$, simultaneous blood glucose being $7.6 \mathrm{mmol} / 1(137 \mathrm{mg} /$ $100 \mathrm{ml})$. The CSF contained $870 \times 10^{6}$ neutrophils $/ 1\left(870 / \mathrm{mm}^{3}\right)$ and $16 \times 10^{6}$ lymphocytes/1. The stained CSF deposit showed many Gram-negative bacilli. $S$ typhi was isolated on culture of the CSF. The results of blood and stool cultures taken during the first and second weeks of the illness were negative for salmonellae. The standard agglutination tests (Widal) done on the fourth, 12th, 20th, and 50th days from the onset of the illness showed persistent, non-rising titres against $\mathrm{O}$ and $\mathrm{H}$ antigens of $S$ typhi and $\mathrm{H}$ antigen of $S$ paratyphi $A$ consistent with previous antityphoid vaccination.

Treatment was started with parenteral penicillin, chloramphenicol, and oral sulphadiazine. When the culture report was available, penicillin and sulphadiazine were replaced by parenteral ampicillin and co-trimoxazole. Pronounced clinical improvement was seen from the third day in hospital. Chemotherapy was continued for 14 days, and the patient was discharged on the 16th hospital day. Over a follow-up of 18 months she has remained in good health.

\section{Comment}

Salmonella meningitis chiefly affects babies and children, ${ }^{12}$ and in the former birth trauma is thought to predispose to infection. ${ }^{2}$ Although several species of salmonellae such as $S$ paratyphi $B, S$ typhimurium, $S$ enteritidis, $S$ choleraesuis, and $S$ panama have been isolated from the cerebrospinal fluid, $S$ typhi has only rarely and sporadically been incriminated as causing purulent meningitis. ${ }^{1-3}$ In most cases $S$ typhi meningitis has occurred as a complication during a typhoidal illness, where fever and bowel symptoms were the presenting features. ${ }^{4}$

Watson $^{5}$ suggested that $S$ typhi bacteraemia was much more common than was thought, and described 12 cases where $S$ typhi was isolated from routine blood or clot culture in patients in whom neither the clinical features, the agglutination titres, nor the necropsy findings indicated a typhoidal illness. Seeding of the organisms in the meninges and their subsequent multiplication may explain the pathogenesis of isolated typhoid meningitis without preceding typhoidal illness. This case draws attention to $S$ typhi as a cause of Gram-negative bacillary meningitis, particularly in typhoid endemic areas.

We thank Professor T E D Chapman for identifying the organism and Miss M Dullewe and Miss V S B C de Mel for secretarial help.

1 Watson, K C, Archives of Disease in Childhood, 1958, 33, 171.

${ }^{2}$ Beene, M L, Hansen, A E, and Fulton, M, American fournal of Diseases of Children, 1951, 82, 567.

${ }^{3}$ Koshi, Grace, and Kurien, T, Indian Pediatrics, 1976, 13, 389.

$4 \mathrm{Kao}, \mathrm{Y}$, and Yeh, M, Chinese Medical fournal, 1962, 81, 260.

5 Watson, K C, Lancet, 1967, 2, 332.

(Accepted 27 September 1977)

Department of Medicine, University of Sri Lanka, Colombo

D CHANMUGAM, MD, MRCP, associate professor of medicine

VASANTHA MACHADO, MD, temporary lecturer in medicine J C L MIHINDUKULASURIYA, MD, registrar

\section{Transplacental hyponatraemia due to oxytocin}

The antidiuretic properties of oxytocin have been described, ${ }^{1}$ and several reports have emphasised the dangers of water intoxication when oxytocin and large amounts of electrolyte-free fluid are administered. We describe a case of maternal water intoxication which occurred after the use of oxytocin in $5 \%$ dextrose for induction of labour, and which resulted in severe hyponatraemia and convulsions in the newborn infant.

\section{Case report}

A healthy 24-year-old primigravida underwent surgical induction of labour at term after a pregnancy complicated by mild hypertension. After rupture of the membranes an intravenous infusion of oxytocin in $5 \%$ dextrose in water was begun, increasing in concentration over four hours from $\frac{1}{2}$ to 4 units of oxytocin per $500 \mathrm{ml} 5 \%$ dextrose, and subsequently given at a rate of 32 milliunits oxytocin per minute. Eighteen hours later, having received a total of 6.5 litres of $5 \%$ dextrose and 36 units of oxytocin, she had a grand mal convulsion. This was controlled with intravenous diazepam, and a liveborn male infant, birthweight $3470 \mathrm{~g}$, was delivered by forceps 15 minutes later. The urine output during labour was 2.7 litres, only 1.3 litres being passed during the 14 hours before delivery. Maternal blood taken after delivery showed plasma concentrations of sodium $117 \mathrm{mmol}(\mathrm{mEq}) / 1$, chloride $86 \mathrm{mmol}(\mathrm{mEq}) / 1$, osmolality $243 \mathrm{mmol}(\mathrm{mOsm}) /$ $\mathrm{kg}$, potassium $3.5 \mathrm{mmol}(\mathrm{mEq}) / \mathrm{l}$, and urea $2.3 \mathrm{mmol} / 1(14 \mathrm{mg} / 100 \mathrm{ml})$. $\mathrm{A}$ diagnosis of water intoxication was made, fluids were withheld, and she had a spontaneous diuresis of 3 litres. Thirty-six hours later the plasma electrolyte concentrations and osmolality were normal and she appeared to have made a full neurological recovery. She returned home on the sixth postpartum day and was perfectly well when seen six weeks postnatally.

At birth the infant was limp and apnoeic, requiring endotracheal intubation and artificial ventilation until spontaneous respirations were established at 10 minutes of age. After transfer to the special care baby unit he developed a raised respiratory rate and was noted to have dystonic limb movements and short episodes of apnoea. From the age of 5 hours he had repeated generalised convulsions. Between fits he had increased extensor tone and further apnoea with cyanosis. Umbilical cord blood taken at delivery showed a plasma sodium concentration of $114 \mathrm{mmol} / 1$ and osmolality $243 \mathrm{mmol} / \mathrm{kg}$, and venous blood taken immediately after the first convulsion showed plasma concentrations of sodium $110 \mathrm{mmol} / 1$ and chloride $81 \mathrm{mmol} / 1$, osmolality $240 \mathrm{mmol} / \mathrm{kg}$, potassium $5.2 \mathrm{mmol} / 1$, calcium $2.1 \mathrm{mmol} / 1(8.4 \mathrm{mg}$ / $100 \mathrm{ml}$ ), magnesium $0.67 \mathrm{mmol} / 1(1.6 \mathrm{mg} / 100 \mathrm{ml})$, and urea $2.7 \mathrm{mmol} / 1$ $(16.3 \mathrm{mg} / 100 \mathrm{ml})$. Lumbar puncture was normal.

His fits were treated with intramuscular phenobarbitone and paraldehyde, but resolved only after correction of his hyponatraemia with twice-isotonic saline given intravenously and fluid restriction. He also received injections of 9-fludrocortisone and magnesium sulphate. In the first $\mathbf{4 8}$ hours of life he passed $240 \mathrm{ml}$ of urine, and by the age of 36 hours the plasma electrolyte concentrations and osmolality had returned to normal and his convulsions had 